\title{
Measles in Bamako: Epidemiological, Clinical and Therapeutic Features of Patients Hospitalized at University Teaching Hospital of Point "G"
}

\author{
Mikaila Kabore $^{1, \text { * }}$, Issa Konate ${ }^{1,4}$, Yacouba Cissoko ${ }^{1,4}$, Bassirou Diarra ${ }^{4,5}$, Jean Paul Dembele ${ }^{1,4}$, \\ Mariam Soumare $^{1}$, Assetou Fofana ${ }^{1}$, Abdoulaye Zare ${ }^{1}$, Hermine Meli ${ }^{1}$, Mohamed Aly Cisse ${ }^{1}$, \\ Dramane Sogoba ${ }^{1}$, Oumar Magassouba ${ }^{1}$, Madou Traore ${ }^{2}$, Kongnimissom Apoline Sondo ${ }^{3}$, \\ Sounkalo Dao 1,4 \\ ${ }^{1}$ Department of Infectious Diseases, Point “G” University Teaching Hospital, Bamako, Mali \\ ${ }^{2}$ Department of Medicine, Sikasso Regional Hospital, Sikasso, Mali \\ ${ }^{3}$ Department of Infectious Diseases, Yalgado Ouedraogo University Teaching Hospital, Ouagadougou, Burkina Faso \\ ${ }^{4}$ Faculty of Medicine and Odontostomatology, University of Sciences, Techniques and Technologies of Bamako (USTTB), Bamako, Mali \\ ${ }^{5}$ Serefo Program, University of Sciences, Techniques and Technologies of Bamako (USTTB), Bamako, Mali
}

\section{Email address:}

mikailakab@gmail.com (M. Kabore), izos_k@yahoo.fr (I. Konate), ycissoko@hotmail.com (Y. Cissoko), bdiarra@icermali.org (B. Diarra), jpdembele@gmail.com (J. P. Dembele), ms.dicko@yahoo.fr (M. Soumare), assetou_fofana@yahoo.fr (A. Fofana),

zareabdoulaye@yahoo.fr (A. Zare), meline20012002@yahoo.fr (H. Meli), cissemedalyoumar@gmail.com (M. A. Cisse),

sogobadramane@yahoo.fr (D. Sogoba), magassoubao@yahoo.fr (O. Magassouba), traoremadou78@yahoo.fr (M. Traore), sondoapoline@yahoo.fr (K. A. Sondo), sounkalod@icermali.org (S. Dao)

${ }^{*}$ Corresponding author

\section{To cite this article:}

Mikaila Kabore, Issa Konate, Yacouba Cissoko, Bassirou Diarra, Jean Paul Dembele, Mariam Soumare, Assetou Fofana, Abdoulaye Zare, Hermine Meli, Mohamed Aly Cisse, Dramane Sogoba, Oumar Magassouba, Madou Traore, Kongnimissom Apoline Sondo, Sounkalo Dao. Measles in Bamako: Epidemiological, Clinical and Therapeutic Features of Patients Hospitalized at University Teaching Hospital of Point "G". International Journal of Infectious Diseases and Therapy. Vol. 4, No. 3, 2019, pp. 44-49. doi: 10.11648/j.ijidt.20190403.13

Received: August 15, 2019; Accepted: September 5, 2019; Published: September 19, 2019

\begin{abstract}
Measles is a highly contagious acute febrile eruptive disease. It can be prevented through vaccination. The aim of this study was to determine the epidemiological, clinical, and therapeutic features of measles cases hospitalized at Point "G" University Teaching Hospital. It was a retrospective study to review the medical files of patients hospitalized for measles between January 2010 and May 2011 at the Infectious Diseases Department of the Point "G" University Teaching Hospital. During the study period, 31 patients (6.4\%) were treated for measles, and the majority of cases were seen in April months (20 cases) and May months (5 cases). The most affected age group was $9-59$ months (58.1\%) with a sex ratio of 1.38 . The majority of patients $(64.5 \%)$ consulted at least two health facilities before their hospitalization in Point " $G$ " with an average of $5.3 \pm 3.6$ days from unset to the hospitalization. Measles immunization was not effective in 16 out of 26 patients and nearly one-third (29.0\%) had familial contact measles case. Febrile rash, present in all patients, was associated with cough (96.8\%), rhinitis $(77.4 \%)$ and/or conjunctivitis $(77.4 \%)$. Pneumonia was the most common complication $(83.9 \%)$ followed by comorbidities such as gastroenteritis $(29 \%)$, malnutrition $(9.7 \%)$ and oral candidiasis $(9.7 \%)$. Amoxicillin and ceftriaxone were the antibiotics frequently used against complications. Patients were hospitalized for an average of $6.9 \pm 4.2$ days, and no death was recorded. This study revealed that pneumonia was the main complication leading to hospitalization of patients. For a better control of measles, we need to fully respect the immunization schedule which is a guarantee for vaccine efficacy.
\end{abstract}

Keywords: Bamako, Clinical, Epidemiology, Therapeutic, Complications, Measles 


\section{Introduction}

Measles is a highly contagious acute febrile eruptive disease. Incidence and mortality have decreased significantly in recent years through routine immunization programs and mass vaccination campaigns [1, 2]. In fact, vaccination prevented 20.4 million deaths between 2000 and 2016 [3]. Notwithstanding these enormous advances, measles still poses a public health problem. It remains an important cause of morbidity and mortality responsible for more than 100,000 deaths per year $[1,4]$.

Africa is the most affected region with nearly $40 \%$ of cases registered in 2015 of which more than two-thirds (69\%) died [1]. In 2010, the World Health Organization (WHO) recorded measles outbreaks in 28 countries of African region, including Mali [5]. During that period, Mali had a total of 1998 suspected measles cases, of which 857 (42.9\%) were positive for immunoglobulin M [6]. After the first mass vaccination campaign in 1998, measles incidence decreased by $95 \%$ in urban districts receiving immunization, but this probably did not affect the overall transmission of measles in Mali [7]. In February 2011, the coverage rate of measles vaccine among children aged 9 - 59 months in Bamako was estimated at $91.3 \%$ according to Ministry of Health. Despite this good coverage, there is measles outbreaks every year. Patients are taken to different health facilities in the country and complicated cases are referred to tertiary hospitals.

The goal of our study was to determine the epidemiological, clinical and therapeutic features of measles cases hospitalized and treated at Point "G" University Teaching Hospital, between 2010 and 2011.

\section{Patients and Methods}

\subsection{Study Design and Sites}

The study was carried out at the Infectious, and Tropical Diseases Department of Point "G" University Teaching Hospital. It is the reference for Infectious and Tropical Diseases within the country. Usually most hospitalized patients are above 15 years old, any age group could be admitted.

The pediatric department of Gabriel Touré University Teaching Hospital is the reference for pediatric and childhood diseases in the country. Almost all patients were first hospitalized there before being joining Point-G because of the various complications associated with measles.

It was a retrospective descriptive study to review medical files of patients hospitalized in Point-G for measles between January 2010 and May 2011.

\subsection{Study Population and Case Definition}

All the complete files of patients hospitalized and treated for measles during the study period were included. Measles was defined as per World Health Organization (WHO): anyone with a generalized rash of maculopapular erythematous type for at least three days with a fever at $38^{\circ} \mathrm{C}$ plus one of the three signs: cough, rhinorrhea or conjunctivitis [8]. For this study, the results of the biological confirmation were not taken into account due to insufficient data archiving.

\subsection{Study Variables}

1. Epidemiological variables: age, sex, residence, history of family contamination, vaccination schedule,

2. Clinical and therapeutic variables: anthropometric parameters, clinical signs, complications and comorbidities, drugs administered,

3. Evolution variables: outcome of hospitalization, length of hospital stay.

\subsection{Data Entry and Analysis}

Individual patients' file, and hospital register were used to collect data and/or information. Thereafter data were entered using EPIDATA entry software and then exported to SPSS (Statistical Package for Social Science) software version 22.0 for window for analysis. Quantitative variables were expressed as mean (standard deviation) or median (range) interquartile (IIQ)] according to the shape of the distribution curve of the values of these variables. The average was calculated when the curve was symmetrical and the median in the opposite case.

Patient records were reviewed and analyzed in accordance with the confidentiality principles. Ethics and good clinical practices were observed at all steps.

\section{Results}

\subsection{Epidemiological Aspects}

During the study period, 31 patients were hospitalized and treated for measles. At the same time, 485 inpatients were recorded for various infectious and tropical diseases, implying a frequency of $6.4 \%$. The cases were notified mainly in April (19 cases in 2010, and 1 case in 2011) and May (4 cases in 2010, and 1 case in 2011) (Figure 1).

The median age of patients was 16 months with an interquartile range (IQR) of nine months and 48 months. The youngest had six months old and the oldest had 25 years old. The age group 9 - 59 months accounted for $58.1 \%$. The sex ratio was 1.38 . The majority of patients come from Bamako (93.5\%) and were referred from the pediatric department of Gabriel Touré University Teaching Hospital (96.8\%).

More than half $(51.6 \%)$ of the patients consulted in two health facilities including Gabriel Touré Hospital before being referred to the infectious and tropical diseases department for better care (Figure 2).

The mean period of inpatient (the period between onset of symptoms and admission to point-g) was $5.3 \pm 3.6$ days with extremes of two and 15 days. According to the mothers' statement, 16/26 patients did not have their up to date vaccination booklet for routine vaccines. Among those who didn't respect the vaccination schedule, two patients $(2 / 16)$ were less than nine months old. Nearly one-third of patients 
(29\%) had a notion of family contact few days before the eruption. All the epidemiological data are presented in Table 1.

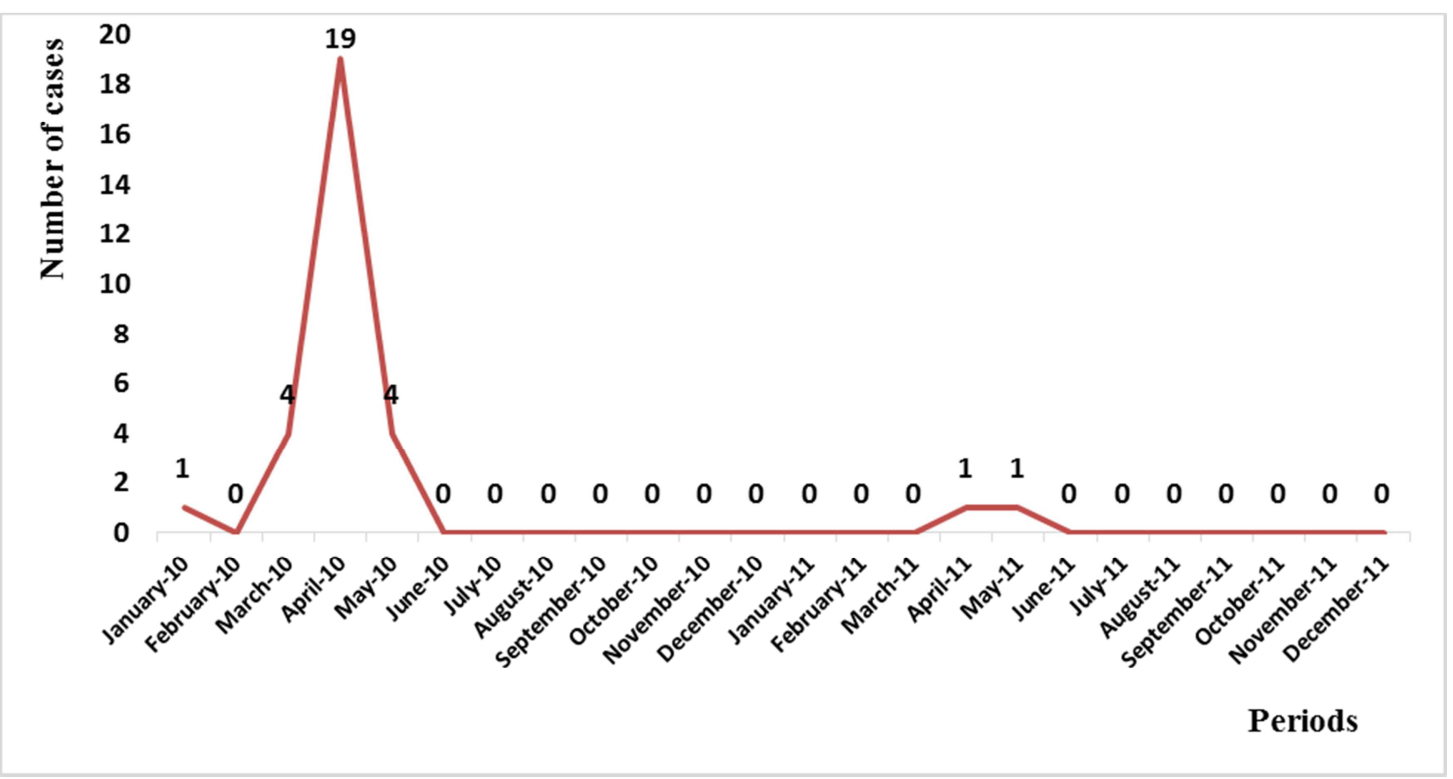

Figure 1. Global Distribution of Measles cases observed by month during the study period.

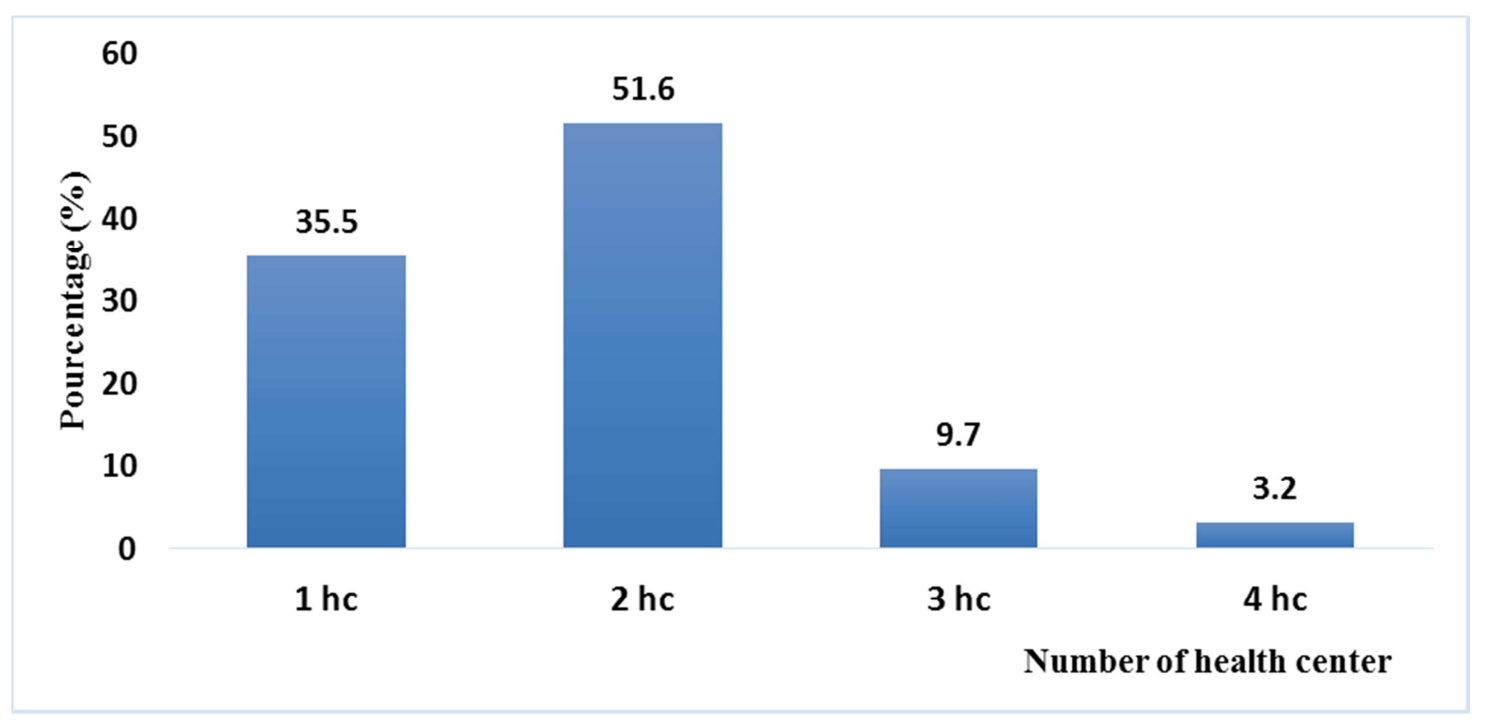

$\mathrm{hc}=$ health center

Figure 2. Itinerary of patients before joining the Infectious Diseases Department of Point "G" University Teaching Hospital.

Table 1. Epidemiological Features of patients.

\begin{tabular}{lll}
\hline Epidemiological variables & Number (n) & Percent (\%) \\
\hline Age groups (months) & & \\
$<9$ & 6 & 19.4 \\
$9-59$ & 18 & 58.1 \\
$\geq 59$ & 7 & 22.6 \\
Sex & & \\
Male & 18 & 58.1 \\
Female & 13 & 41.9 \\
Place of residence & & \\
Bamako & 28 & 93.5 \\
Kati & 2 & 6.5 \\
Immunization schedule & & \\
Up to date & 11 & 35.5 \\
Not up to date & 16 & 51.6 \\
Unspecified & 4 & 12.9 \\
Concept of measles contamination & & \\
\hline
\end{tabular}

\begin{tabular}{lll}
\hline Epidemiological variables & Number (n) & Percent (\%) \\
\hline Yes & 9 & 29.0 \\
No & 22 & 71.0 \\
Origin & & \\
Gabriel Toure Teaching Hospital & 30 & 96.8 \\
Reference Health Center & 1 & 3.2 \\
\hline
\end{tabular}

\subsection{Clinical Aspects}

At admission, all patients had a febrile rash, very often associated with cough (96.8\%), rhinitis (77.4\%) and conjunctivitis $(77.4 \%)$. Koplik's sign was reported on the oral cavity in more than half of patients $(58.1 \%)$. The complications, mainly pneumonia $(83.9 \%)$ were the main reasons for the referral of patients from the Pediatric Department to Infectious and Tropical Diseases Department. 
Furthermore, some patients had comorbidities, and the most frequent being gastroenteritis $(29.0 \%)$, malnutrition $(9.7 \%)$, malaria $(9.7 \%)$, including two cases with neurological signs and oral candidiasis $(9.7 \%)$. Clinical data are reported in Table 2 .

Table 2. Clinical Features of patients.

\begin{tabular}{lll}
\hline Clinical variables & Number (n) & Percent (\%) \\
\hline Clinical manifestation & & \\
Skin rash & 31 & 100 \\
Fever & 31 & 100 \\
Cough & 30 & 96.8 \\
Rhinitis & 24 & 77.4 \\
Conjunctivitis & 24 & 77.4 \\
Koplik's sign & 18 & 58.1 \\
Comorbidities & & \\
Gastroenteritis & 10 & 29.0 \\
Malnutrition & 3 & 9.7 \\
Oral candidiasis & 3 & 9.7 \\
Malaria & 3 & 9.7 \\
Dermatophytosis & 2 & 6.5 \\
Purulent otitis & 2 & 6.5 \\
Ischemic stroke & 1 & 3.2 \\
Complications & & \\
Pneumonia & 26 & 83.9 \\
Febrile seizures & 3 & 9.7 \\
Dehydration & 3 & 9.7 \\
\hline
\end{tabular}

\subsection{Therapeutic and Evolutionary Aspects}

For treatment, amoxicillin in $93.5 \%$ cases and ceftriaxone in $12.9 \%$ in general route were the most used antibiotics for the management of complications, particularly pulmonary. Conjunctivitis was treated or prevented by gentamycin eye drops in almost $2 / 3$ of patients $(64.5 \%)$. The other treatments consisted mainly of relieving patients from fever $(83.9 \%)$, improving oral hygiene with antiseptics $(22.6 \%)$, treating cough (19.4\%) and intestinal deworming (12.9\%). Only two patients received Vitamin A therapy. All the therapeutic features are shown in Table 3.

Table 3. Therapeutic features of patients.

\begin{tabular}{lll}
\hline Treatments & Number (n) & Percent (\%) \\
\hline General route antibiotics & & \\
Amoxicillin & 29 & 93.5 \\
Ceftriaxone & 4 & 12.9 \\
Metronidazole & 1 & 3.2 \\
Gentamicin & 1 & 3.2 \\
Antibiotics in eye drops & & \\
Gentamicin & 20 & 64.5 \\
Rifamycin & 7 & 22.6 \\
Other treatments & & \\
Analgesic/antipyretic & 26 & 83.9 \\
Oral antiseptic & 7 & 22.6 \\
Expectorant/antitussive & 6 & 19.4 \\
Antiparasitic & 4 & 12.9 \\
Antimalarial & 3 & 9.7 \\
Antifungal & 3 & 9.7 \\
Vitamin A & 2 & 6.5 \\
Dexamethasone & 2 & 6.5 \\
Other* & 4 & 12.9 \\
\hline
\end{tabular}

*Other: Nasal decongestant (2), acyclovir (1), metopimazine (1).
At the end of the hospitalization, no deaths were recorded. The average duration of stay was $6.9 \pm 4.2$ days with extremes of three days and 27 days. The majority of patients $(58.1 \%)$ stayed less than one week in hospital.

\section{Discussion}

\subsection{Epidemiological Aspects}

We conducted a retrospective study on measles cases managed between January 2010 and May 2011 in the Infectious and Tropical Diseases Department of Point "G" University Teaching Hospital. During the study period, measles accounted for $6.4 \%$ of overall inpatients. Our frequency is similar of that of Camara [9] in Senegal who found $6.63 \%$, but higher than those of Isezuo [10] 3.3\% and Onyiriuba [11] both in Nigeria of 3.3 and $3.1 \%$ respectively. The context, study design and period could explain these differences. The outbreaks were mainly observed in April and May, during both year 2010 and 2011. This finding, as in other studies [10-13], confirms that the disease is much more prevalent in the dry season (Harmattan period). This is a good time for the development and outbreak of airborne diseases such as measles, which is highly contagious through the projection of nasolaryngeal secretions from patients during coughing and sneezing [1, 3]. Measles outbreak response plans should consider this parameter for better planning.

The average hospitalization time was $5.3 \pm 3.6$ days with extremes of two and 15 days. This time is justified by the itinerary followed by patients in different health facilities before been inpatient to the referral service [13]. Indeed, in our study, more than half of the patients consulted in two health centers before being referred to us. This is usually the case of measles with complications that are hospitalized in specialized structures, the majority being treated at remote facilities. Thus, in Benin, of 36,726 measles cases reported in three years (1993-1995), only 8.7\% were hospitalized for various complications [14]. Mostly, our patients were young with a median age of 16 months. The age group of nine to 59 months was the most affected $(58.1 \%)$. The same observation was made by Sume [15] in their study. Several African authors [9-11, 13, 15-19] have also concluded that measles is a childhood disease. It is important to increase routine immunization coverage and targeted mass campaigns at this age group to reduce further the incidence of measles morbidity and mortality [3]. Nevertheless, Boushab [20] found the over-20s as being the most affected by the disease in their study at a regional hospital in Mauritania. Measles is more prevalent in males, and this was the same observation in our study and the conclusion of many other authors during their work [9-11, 13, 16-19]. The reasons are not clearly understood.

Respect of the immunization schedule by the mothers was verified in 26 patients and among them, 16 wouldn't have had a measles vaccine. This result is comparable to those of Aliyu [13] and Onyiriuka [12] all in Nigeria, which found 
$60.7 \%$ and $77.9 \%$ respectively, and Camara [13] in Senegal who reported $71.2 \%$ of children not immunized against measles. Djadou [16] at al., however, reported a proportion of $53 \%$ of sick children who had received at least one dose of measles vaccine. These different results emphasize the importance of respecting the administration of at least two doses of measles vaccine to ensure optimal protection against the disease. In addition, the unset of measles in vaccinated children could be explained, beyond the incompleteness of the vaccination scheme, by stock-outs; the inefficacy of previous administered doses because of the abnormal storage condition of the vaccine, and also by the insufficient response of the immune system to the vaccine antigens $[4,13,14]$. The occurrence of measles before 9 months old, as was seen in two cases of our patients, could be explained by a lack of post-vaccination or post-infectious immunization in mothers, which is essential for the transfer of antibodies to children. However, the decrease of maternal antibodies before nine months in children, up to a non-protective threshold may also be the reason. This poses the problem of the choice of perfect moment for measles immunization of children in an endemic and poverty context. The concept of family contact of measles was observed in $29 \%$ of patients. This observation has been made by other authors in their studies $[9,11,20]$.

\subsection{Clinical Aspects}

Clinically, all patients had febrile rash according to the WHO criteria associated with cough $(96.8 \%)$, rhinitis (77.4\%) and/or conjunctivitis (77.4\%). Our results are similar to other authors such as Sume [15] in Cameroon and Doutchi [17] in Niger. Pneumonia was the main cause of morbidity and mortality associated with measles [1]. In our study, pneumonia was found in $83.9 \%$ of cases, followed by other comorbidities such as gastroenteritis $(29.0 \%)$, malnutrition $(9.7 \%)$, oral candidiasis $(9.7 \%)$. These observations have also found in other African studies [9, 10, 13, 17, 20].

Only three cases of malaria $(9.7 \%)$ were diagnosed in our patients and were not reported by other authors $[13,17]$. The low frequency of malaria cases is explained by the period of measles occurrence which is not the same as for malaria, which occurs mainly in rainy season. Three patients had seizures possibly due to fever, which is usually most frequent during measles and malaria, but can also be explained by brain damage caused by the virus. Seizures, whatever the cause, are bad prognosis factors $[9,17,20]$.

\subsection{Therapeutic and Evolutionary Features}

Amoxicillin, ceftriaxone, gentamycin and metronidazole were the antibiotics used for the management of complications including pneumonia, gastroenteritis and purulent otitis. It has been well demonstrated that systemic administration of antibiotics in children with measles prevent the occurrence of pneumonia, ear infections and tonsillitis without any significant effect on diarrhea [21]. Conjunctivitis was treated or prevented by gentamycin eye drops in almost $2 / 3$ of patients (64.5\%). Vitamin A was administered to only two of our patients. However, WHO routinely recommends two doses of Vitamin A for all children with measles [3]. The unavailability of the drug or its inaccessibility during the period could explain its scarcity of use in children in our series.

At the end of the hospitalization, no case of death was recorded. However, Djadou et al. [16], Camara et al. [13] as well as Doutchi et al. [17] noted a lethality rate respectively $13 \% ; 7.69 \%$ and $2.52 \%$. Measles is a serious disease [3] and we believe that deaths have occurred in the community or in pediatric department of Gabriel Touré Hospital, from which most patients have been referred. Our patients stayed an average of one week (6.9 days) in the department. Doutchi [17] as well as Camara [13] found similar results (6.5 days and 7.6 days, respectively). As for Djadou [16], their patients stayed on average 4.5 days. Early mortality during the management of measles helps to shorten the hospital stay of patients. The highest lethality rate recorded in the study of Djadou could explain the shorter stay of their patients compared to ours.

\section{Conclusion}

Measles remains a public health problem in Mali and many countries in the WHO African Region. It mainly affects unimmunized children under the age of five, especially during the dry season. Clinical signs were the rash frequently associated by otorhinolaryngology, pulmonary and ocular disorders. Pneumonia was the main complication and the main reason for patients' admission in our study sometimes due to diagnosis delay. Its management has been effective with amoxicillin or ceftriaxone and no deaths were reported. The respect of the immunization schedule remains erratic in our settings, but it's the only way of preventing measles.

\section{Competing Interests}

The authors declare that they have no competing interests.

\section{Author Contributions}

M. K.: drafting the article.

I. K. and Y. C.: review of the literature, correction of the document.

J-P. D., M. S., A. F., A. Z., H. M., M. A. C., O. M., D. S., M. T., B. C., F. K., K. A. S.: reading the document.

B. D.: reading and translation of the document in English.

S. D.: correction and approval of the final version of the document.

\section{References}

[1] Moss WJ. Measles. The Lancet. 2017; 390 (10111): 2490-502.

[2] Byberg S, Thysen SM, Rodrigues A, Martins C, Cabral C, Careme $\mathrm{M}$, et al. A general measles vaccination campaign in urban Guinea-Bissau: Comparing child mortality among participants and non-participants. Vaccine. 2017; 351: 33-9. 
[3] WHO. Measles [Internet]. WHO; 2018. Available on: https://www.who.int/news-room/fact-sheets/detail/meales [accessed 12 december 2018].

[4] Saleh J-E. Trends of measles in Nigeria: A systematic review. Sahel Medical Journal. 2016; 19 (1): 5-11.

[5] OMS. Élimination de la rougeole d'ici 2020: Stratégie pour la Région africaine. In 61ème session du Comité régional de l'OMS pour l'Afrique, Yamoussoukro, Côte d'Ivoire, 29 août - 2 septembre 2011. OMS, Bureau régional de l'Afrique; 2011.

[6] Ministère de la santé. Plan stratégique d'élimination de la rougeole au Mali (2013 - 2020) [Internet]. Direction nationale de la Santé; 2013. Available on: http://www.nationalplanningcycles.org/sites/default/files/plann ing_cycle_repository/mali/plan_strategique_elimination_roug eole_sikasso_mali_2013_2020_21-08-013_vf_0.pdf [accessed 1 may 2018].

[7] Kertesz DA, Touré K, Berthé A, Konaté Y, Bougoudogo F. Evaluation of Urban Measles Mass Campaigns for Children Aged 9-59 Months in Mali. The Journal of Infectious Diseases. 2003; 187 (Suppl 1): 69-73.

[8] OMS. Le traitement de la rougeole chez l'enfant. WHO/EPI/TRAM/97.02; 2004.

[9] Camara B, Diouf S, Diagne I, Tall Dia A, Fall L, Ba M, et al. Complications de la rougeole et facteurs de risque de décès. Médecine d'Afrique Noire. 2000; 47 (8/9): 380-5.

[10] Sezuo K, Yusuf T, Ibitoye P, Sanni M, Jiya N, Sani U, et al. A 5 -year review of measles cases admitted into the emergency paediatric unit of a tertiary hospital in Sokoto, North-Western Nigeria. Sahel Medical Journal. 2018; 21 (3): 122-7.

[11] Onyiriuka AN. Clinical profile of children presenting with measles in a Nigerian secondary health-care institution. Journal of Infectious Diseases and Immunity. 2011; 3 (6): $112-6$.

[12] Imperato PJ. Traditional attitudes towards measles in the Republic of Mali. Transactions of the Royal Society of Tropical Medicine and Hygiene. 1969; 63 (6): 768-80.
[13] Aliyu I. Clinical findings and outcome of measles outbreak in an African city. Sifa Med J. 2016; 3 (1): 1-4.

[14] Fourn L, Fayomi E, Zohoun T. Rougeole: un défi pour le programme élargi de vaccination au Bénin. Médecine d'Afrique Noire. 1998; 45 (1): 6-8.

[15] Sume GE, Fouda AAB, Kobela M, Nguelé S, Emah I, Atem P, et al. Epidemiology and clinical characteristics of the Measles outbreak in the Nylon Health District, Douala Cameroon: a retrospective descriptive cross sectional study. Pan Afr Med J. 2012; 13: 66 .

[16] Djadou K, Wateba M, Tchagbele $O$, Agbèrè A-D, Saka D, Atakouma Y. Aspects actuels de la rougeole dans le service de pédiatrie au CHR de Tsévié (CHR-T), de 2010 à 2012. Rev CAMES SANTE. 2013; 1 (2): 90-2.

[17] Doutchi M, Mohamed A-AO, Sayadi S, Sibongwere D, Shepherd S, Nafissa OM, et al. Campagne de vaccination contre la rougeole en période de pic épidémique dans une zone à forte prévalence de malnutrition au Niger: cas du district sanitaire de Mirriah (Zinder). Pan African Medical $\begin{array}{llll}\text { Journal. } & 2017 ; & 27: & 240 .\end{array}$ 10.11604/pamj.2017.27.240.11881.

[18] Goodson JL, Masresha BG, Wannemuehler K, Uzicanin A, Cochi S. Changing Epidemiology of Measles in Africa. Journal of Infectious Diseases. 2011; 204 (Suppl 1): 205-14.

[19] Seck I, Faye A, Mbacké Leye MM, Bathily A, DiagneCamara M, Ndiaye P, et al. Épidémie de rougeole et de sa riposte en 2009, dans la région de Dakar, Sénégal. Santé Publique. 2012; 24 (2): 121.

[20] Boushab BM, Savadogo M, Sow MS, Dao S. Epidemiological, clinical, and prognostic study of the measles in the Aioun regional hospital in Mauritania. Médecine et Santé Tropicales. 2015; 4-5-6; (2): 180-3.

[21] Kabra SK, Lodha R. Antibiotics for preventing complications in children with measles. In: The Cochrane Collaboration, éditeur. Cochrane Database of Systematic Reviews [Internet]. Chichester, UK: John Wiley \& Sons, Ltd; 2008. Available on: http://doi.wiley.com/10.1002/14651858.CD001477.pub3 [accessed 14 November 2018]. 